\title{
Discussion on the Course of College Students' Mental Health Based on Positive Psychology
}

\author{
Tian-lin CHEN \\ Psychological Counseling Center \\ Jiangxi University of Traditional Chinese Medicine \\ Nanchang, Jiangxi, China \\ Lan LUO \\ School of Humanities \\ Jiangxi University of Traditional Chinese Medicine \\ Nanchang, Jiangxi, China
}

\author{
Zhen LI \\ Graduate School \\ Jiangxi University of Traditional Chinese Medicine \\ Nanchang, Jiangxi, China \\ Xiao-fei XIAO * \\ Higher Education Research Office \\ Jiangxi University of Traditional Chinese Medicine \\ Nanchang, Jiangxi, China \\ 289241871@qq.com
}

\begin{abstract}
To discuss the application of positive psychology in the course of college students' mental health, this paper analyzes the positive psychology into the course of college students' mental health, which is not only consistent with the characteristics of physical and mental development of college students, but also is the result of the internal needs of college students who pay more attention to the development of self. Therefore, according to the theory of positive psychology and the physical and mental characteristics of contemporary college students, in order to integrate positive psychology into college students' mental health better, te achers should actively transform their educational ideas, cultivate their positive qualities and create positive classroom atmosphere. In the process of mental health education, four aspects should be emphasized: the cultivation of positive personality, emotional education, the guidance of interpersonal relationships, nurturance of resistance to frustration and so on.
\end{abstract}

Keywords-positive psychology; college students; course of mental health

\section{INTRODUCTION}

As a new research field in psychology, positive psychology advocates a positive way to interpret human psychological phenomena. While paying attention to the negative level of psychological problems, more attention should be paid to the stimulation and excavation of the positive potential of the individual. It is believed that the individual positive psychology itself has the role of prevention and treatment of psychological problems[1]. However, as the main position of college mental health education, the course of college students' mental health still uses the traditional "pathology" education model, mainly aiming at psychological problems and basic adaptation problems. This makes students mistakenly believe that mental health education is only for those with mental illness, so they are unwilling to participate actively, and there's no good educational effect.

How to improve the course of college students' mental health? Positive psychology believes that the course of college

Project supported by the subject of teaching reform of College in Jiangxi province (NO. JXJG-2014-12-16)

Corresponding author: Xiao-fei XIAO students' mental health should be set it as a goal to stimulate the inner and positive forces of the students, so as to enhance students' positive emotional experience and eventually form a stable positive personality[2]. Therefore, it is a supplement to the traditional psychological health education to study the course of College Students' mental health based on positive psychology.

\section{The Psychological Basis of Integrating Positive Psychology into the CouRse of College Students' Mental Health}

Positive psychology puts the psychological research focus on the positive qualities and the potential ability of human beings. Therefore, only to construct a positive psychological education model for college students by leading positive psychological ideas into the course of college students' mental health, the goal of college students' mental health education can be balanced. And college students can get real health by developing their positive psychological factors at the same time as treatment and correction of their mental problems. It has its psychological basis to integrate positive psychology into the course of college students' mental health and build a positive mental health education model.

Firstly, college students are in the stage of transition from late youth to adulthood, and they have a great psychological potential. The education model of positive psychology identities the potential of human beings and takes it as its logical starting point, and takes the potential development and creativity as its important task.

Secondly, college students are positive, and have many kinds of needs, such as success, knowledge, happiness and well-being, which are the driving force of their behaviors, the main motivation for them to pursue health, success, happiness and well-being, and the source of their enthusiasm. Positive mental health education recognizes and emphasizes the importance of the basic needs of people. On the basis of meeting the basic needs of college students, it stimulates the students to produce positive psychological needs as far as 
possible, so that students have a positive intention, desire, motivation, aspirations, interests, beliefs and values.

Thirdly, college students attach importance to self development. They are eager to recognize and objectively evaluate them, to be independent and to be self- constrained, self-determined, and self-actualization. Positive mental education acknowledges the desire and ability of selfdevelopment of college students, and takes it as the premise of psychological education. By providing opportunities and creating conditions to form a correct self-consciousness of college students, so that can promote their healthy growth and development. Therefore, it has sufficient psychological basis to adopt positive psychological education in the course of college students' mental health.

\section{REQUIREMENTS FOR THE IMPLEMENTATION OF THE COURSE of College Students' Psychological Health Education UNDER THE POSITIVE CONCEPT}

Positive psychology believes that the most effective way to develop an individual's positive personality, positive strength and positive quality is to improve the positive experience of the individual. When an individual has more experience, he will put forward higher requirements for himself. At the same time, because this requirement comes from the inside of the individual, it is easier to form some personality characteristics. Therefore, in the teaching, research and practice activities of College Students' positive mental health course, teachers should take positive educational attitude and teaching means to enhance the positive experience of college students, and provide high-quality teaching services for students.

\section{A. Actively Change the Idea of Education}

In order to carry out the course of college students' positive mental health, we should firstly change the educational idea of the school on the basis of positive psychology theory. In traditional education, teachers are accustomed to help students analyze problems and deficiency through critical education. The positive education advocated by positive psychology advocates that teachers should be good at finding positive aspects of students, and treat students with encouragement and appreciation, supplemented by criticism and punishment, so as to cultivate students' positive qualities. The purpose of education is to promote the overall development of people's body and mind, so that most people can enjoy the happiness brought by education. However, education is open to all the students, not only for those who have problems, but also for normal healthy students. They also need to make their lives better. Therefore, in the process of education, we should change the concept of education and strive for environment for the students which can make the best quality of their performance.

\section{B. Create a Positive Atmosphere in the Classroom}

To carry out the course of positive college students' mental health education, we should pay attention to creating a positive classroom. That is, in the teaching and learning activities in the classroom, we can create a positive atmosphere in class, so that students can get good, enough and positive emotional experience in classroom learning. Pay attention to the individualized teaching, which make the students acquire the gains and success in learning, and get the emotional pleasure of the subject at the same time.

\section{Pay Attention to the Positive Psychological Quality of Teachers}

In order to carry out the positive mental health education course for college students, teachers themselves must have positive psychology and good mood, pay attention to their mental outlook and actions, and win their own respect and love through their practical actions. As long as all teachers can take positive psychological education as a mission, improve their psychological quality, de velop their abilities and tap their inner potential in the process of education, they can improve their psychological quality. In turn, teachers can use certain methods to adjust the mental state of students' learning, so that they can often be in a positive situation, learn and think actively. In this way, the teachers and students can communicate and interact effectively, then it becomes a virtuous circle. In this process, the course should mainly find or create an environment for students, so that the best quality of students can be fully displayed and exerted in this environment.

\section{Course Content of College Students' Positive Mental Health Education}

According to the theory of positive psychology and Chinese Contemporary College Students' physical and mental characteristics, living and learning content, the course of college students' positive mental health education should emphasize the following four aspects: the cultivation of positive personality, emotional education, The guidance of interpersonal relationships, nurturance of resistance to frustration.

\section{A. The Cultivation of Positive Personality}

Positive personality, as a driving force in personality, can not only prevent the destructive effect of negative personality, but also promote the development of people's adaptive ability and safeguard people's physical and mental health. Some scholars in our country have carried out some research on the mental health level of college students and their positive qualities. For example, Juan-juan WEN [3] research shows that the mental health level of the subjects with high optimism and low pessimism is the highest, while those with low optimism and high pessimism have the lowest mental health level. These similar studies have strongly proved that the positive personality traits as the motive force of personality have an important influence on the mental health of college students. Students own positive power will not grow If our mental health education is only to help them eliminate the negative aspects of problems, or personality problems or even personality, even if all his problems are eliminated. Only by taking the formation of College Students' positive personality quality as the main educational content of college mental health curriculum, can we cultivate and grow the positive force of college students, promote their adaptive ability and maintain their mental health. 


\section{B. Emotional Education}

In the past, psychology was focusing on negative emotions and the psychological diseases it caused, but positive and positive emotions are now being paid attention to. The study of Xin-bo WANG [4] shows that when the positive emotions are experienced, the behavior goals of college students are often positive and vivid. Emotional education is to enable students to enjoy physical and mental education. College students' emotion is in a period of rapid development, they have rich and complex emotional world, emotional experience is fast and intense. Once their emotions are triggered, they are prone to resonate. On the other hand, if their emotions are frustrated, they are depressed, pessimistic and disappointed. Therefore, emotional education is of great significance to the healthy growth of college students. Emotional education should firstly guide college students to adjust and control their own emotions, learn to maintain a peaceful mood and avoid the emergence of negative passions. Secondly, we should pay attention to stimulating the positive emotional experience of college students, especially the experience of self esteem and self-confidence. This is the emotional experience formed by the full understanding and high evaluation of the self value, and the inner source of the development of the personality. Thirdly, we should pay attention to the cultivation of social emotion of college students. Because social emotion reflects the attitude and inner experience of people's social relations, social conditions and social cultural characteristics.

\section{The Guidance of Interpersonal Relationships}

Interpersonal communication is the basic condition for the healthy growth of young people[5]. It is necessary to cultivate their attitude to identify others and maintain positive interpersonal communication. Interpersonal relationship is of great significance to the healthy growth of college students: Firstly, it can meet the primary psychological needs of college students. The pursuit of self - worth and sense of security is the fundamental and primary need of human beings. The optimistic mood is the symbol of the harmony of the body and mind, also the important symbol of the mental health. Modern science further proved that optimism can function the nervous system, the endocrine system in the best state of automatic adjustment, in the meanwhile be conducive to the promotion of psychological activity such as human perception, memory, imagination, thinking. While the negative emotions such as anger, secretion to fear and anxiety will make the body be inhibition of adrenal cortical hormone, which reduced immunity of the human body. If negative emotions can't be alleviated in a long term, that will cause various neurosis, resulting in daily life disorder, disruption of normal social function.

\section{Nurturance of Resistance to Frustration}

With the continuous development of society and the reform of higher education system, some students are frustrated by their subjective desire and objective reality, ideal and reality. Frustration can easily lead to their negative behavior, such as withdrawal, sensitive, attack and so on, this will tend to bias their personality[6]. We should put right attitudes towards the setbacks of college students, which have a positive impact on college students. Firstly, setbacks can enhance the beneficial effect of College Students' psychology. Frustration is an internal drive, which can push individuals to make greater efforts to achieve their goals and spend more energy. Secondly, setbacks can enhance the tolerance of college students. The ability of an individual's tolerance for frustration is related to the experience of frustration in the past. If individuals go all the way since the childhood, never been faced failure or misfortune, or escaping once suffering a setback, they will have little tolerance. The individuals who suffer setbacks more, their tolerance for setbacks will increase. Thirdly, setbacks can improve the level of College Students' understanding. When a person has faced with setbacks and failures, he will often sum up experience, change strategy, to achieve the ultimate goal, the so-called "a fall into the pit, a gain in your wit".

\section{CONCLUSION}

In conclusion, the course of college students' mental health based on positive psychological concept should be aimed at cultivating college students' good psychological quality and promoting the all-round development of College Students' physical and mental health. The contents include the imparting of psychological knowledge, the cultivation of psychological quality and psychological guidance. According to the characteristics and laws of students' physical and mental development, by the specialized curriculum with psychology literacy educators, its purpose is to promote the mental health of college students, cultivate students' good psychological quality, promote the all-round development.

\section{REFERENCES}

[1] Yan BAI. Research on psychological health education of college students from the perspective of positive psychology [D]. Beijing University of Chemical Technology, 2013. (In Chinese)

[2] Jing-fang XIANG. The application of positive psychology to psychological health education of college students [D]. Chongqing Jiaotong University, 2013.(In Chinese)

[3] Juan-juan WEN. Research on the training of positive psychological quality of college students [J]. Chinese special education, 2014 (11):1516. (In Chinese)

[4] Xin-bo WANG. Research on psychological health education of college students based on positive psychology [D], Suzhou University, 2015(In Chinese)

[5] Luthans F, Stajkovic AD, Ibrayeva E.Environmental and Psychologichal Challenges Facing Entreoreneurial Development in Transition Economines. Journal of World Business, 2000, 35:95-110.

[6] Colin Jones, Jack. A contemporary approach to entrepreneurship education[J].Education and Training, 2004, vol(46). 